\title{
AMOR RUIBAL Y LA TIPOLOGÍA LINGÜÍSTICA*
}

\author{
Javier Arias Navarro \\ Universität Hamburg
}

\section{PREÁMBULO}

Tal vez cumpla, en el inicio de esta conferencia, constatar la perplejidad que provoca el hecho de que, hasta la fecha, una obra como la de Ángel Amor Ruibal, extraordinaria tanto por su volumen como por su densidad conceptual, haya pasado por completo inadvertida en el ámbito de la filología española e hispánica. ¿Será ello una prueba de la verdad de aquel jocoso comentario de José Ortega y Gasset (1883-1955), según el cual los lingüistas son, después de los aviadores, los seres de este mundo menos propensos al

* El presente texto es una versión notablemente ampliada de la conferencia que pronuncié en la sede del Consello da Cultura Galega el día 16 de diciembre de 2005, con ocasión del Simposio Internacional sobre a Obra Filolóxico-Lingüística de Ángel Amor Ruibal (1869-1930). He optado por mantener -en la medida de lo posible y cuando ello no dañaba el rigor argumental- la retórica algo fatua y enfática que a una charla o conferencia se le exige como diezmo de la oralidad. Alguna redundancia acaso encuentre disculpa también en este hecho. Se han añadido notas aclaratorias allí donde era necesario. Ni que decir tiene que el presente texto se ha beneficiado enormemente del debate con los otros colegas conferenciantes y con los demás asistentes al citado simposio. Quede expresa aquí mi gratitud por lo mucho que de ellos pude aprender en aquellos fríos días compostelanos.

1. El comentario, que se encuentra repetidas veces a lo largo de la obra de Ortega, surge a propósito del debate sobre el carácter más o menos unitario atribuido al latín vulgar, y se formula en los siguientes términos: «El otro carácter aterrador del latín vulgar es precisamente su homogeneidad. Los lingüistas, que acaso son, después de los aviadores, los hombres menos dispuestos a asustarse de cosa alguna, no parecen inmutarse ante el hecho de que hablasen lo mismo países tan dispares como Cartago y Galia, Tingitania y Dalmacia, Hispania y Rumania. Yo, en cambio, que soy bastante tímido, que tiemblo cuando veo cómo el viento fatiga unas cañas, no puedo reprimir ante ese hecho un estremecimiento medular. Me parece sencillamente atroz» («Prólogo para franceses», en J. Ortega y Gasset, La rebelión de las masas, Alianza Editorial, Madrid, 1979 , p. 31; cursivas añadidas).

Atroz resulta, en todo caso, que su audacia u osadía -casi proverbial, al parecer- lleve a los lingüistas a mirar para otro lado y a no darse por aludidos cuando se trata de 
asombro, a asustarse o maravillarse de cosa alguna? ${ }^{1}$ Sea como fuere, los motivos de la aludida ceguera (que llega a ser, de hecho, absoluto desconocimiento del nombre y la figura de Amor Ruibal) son variados y, sin duda, dignos de estudio. Tanto más cuanto que por aquellos años (a principios del siglo xx, más o menos) se estaba decidiendo -a través de la obra de autores del indudable calibre de Ramón Menéndez Pidal (1869-1968)- la dirección que en nuestro país habría de tomar la lingüística (entendida en estrecho sentido filológico) durante varios decenios ${ }^{2}$. Creo que sería iluminador el estudio de las razones históricas, sociológicas, culturales en general, que han conducido a la situación descrita. Ésa no es, con todo, una cuestión sobre la que yo pueda detenerme a pensar aquí. Acaso otros ponentes nos hayan ofrecido ya, cuando pronuncio estas palabras, algunas pistas; o quizá en las sesiones restantes se nos presenten razones de peso que nos eximan de considerar este olvido un mero fruto del azar... Quede dicho, empero, que se trata de una tarea que debe emprenderse en algún momento y con la máxima

habérselas con trabajos de la envergadura y la significancia de los de Amor Ruibal. No importa qué obra de referencia consultemos: el nombre de nuestro autor no aparece por ninguna parte. Y la ignorancia y el descuido se hacen extensivos a estudiosos que, por lo general, constituyen verdaderos ejemplos de seriedad, como Pieter A. Verburg (1905-1989) o Jürgen Trabant. Así, en una reciente obra de Trabant (Mithridates im Paradies: Kleine Geschichte des Sprachdenkens, Beck, Munich, 2003), donde se dedican numerosas páginas a Hervás y Panduro, no se alude en ningún momento a Ángel Amor Ruibal ni a su obra lingüística, a pesar de que se le presta atención pormenorizada a la tradición filológica alemana del siglo xix (de la que tanto se nutrió el autor gallego). Tanto más llamativa es la omisión de la figura de don Ángel cuanto que Trabant ofrece-frente a lo que suele ser práctica habitual en nuestros días- cumplida cuenta de las diferentes teorías del signo, entre las que, a nuestro entender, la original modulación que Amor Ruibal ofrece de las ideas escolásticas habría debido encontrar cobijo.

2. Como el lector sabrá, se suele convenir en considerar que la Fonología española (Gredos, Madrid, 1950) de Emilio Alarcos Llorach (1922-1998) y Estructura del sistema de aspectos y tiempos del verbo griego antiguo (CSIC: Colegio Trilingüe [de la Universidad de Salamanca], Salamanca, 1954) de Martín Sánchez Ruipérez, son los mojones que señalan el inicio de los estudios lingüísticos de índole estructuralista en nuestro país. Aunque ello no supone, ni mucho menos, la desaparición de la labor del Centro de Estudios Históricos (con el que los citados autores estuvieron de un modo u otro vinculados), sí marca el fin de su dominio en solitario de la escena filológico-lingüística. 
seriedad. De tal esfuerzo formaría parte, por cierto, la aclaración del prolongado silencio que, en lo que a la lingüística se refiere, mantuvo Amor Ruibal entre el año 1905 (que hoy nos sirve para rememorarlo) y el día de su muerte ${ }^{3}$.

Hasta ahora, un breve artículo, aunque denso, del profesor Antonio Domínguez Rey era lo único que sobre la obra lingüística y filológica de Amor Ruibal nos era dado leer ${ }^{4}$. El repaso de algunos de los relativamente numerosos escritos sobre su obra

3. Dicho silencio no se refiere, desde luego, a sus preocupaciones filosóficas. Precisamente en el período en cuestión ven la luz los seis primeros volúmenes de Los problemas fundamentales de la filosofía y del dogma (Tipografía de El Eco de Santiago, Santiago de Compostela, 1914-1921).

Por lo demás, no parece aventurado suponer que al silencio en asuntos de lingüística -apenas matizado por alguna entrevista en la prensa y por las noticias sobre su interés en trabajar en un diccionario etimológico del gallego, del que apenas parecen conservarse una docena de cuartillas con fichas y bosquejos- hubo de contribuir el desánimo y desilusión producidos por el silencio con que en el ámbito filológico español se acogió su opus magnum (Los problemas fundamentales de la filología comparada. Su historia, su naturaleza y sus diversas relaciones científicas. Primera Parte, Consello da Cultura Galega, Santiago de Compostela, 2005 [princeps, 1904]; Los problemas fundamentales de la filología comparada. Su historia, su naturaleza y sus diversas relaciones científicas. Segunda Parte, Consello da Cultura Galega, Santiago de Compostela, 2005 [princeps, 1905]). Nota: a partir de ahora emplearemos las siglas «PFFC I» $\mathrm{y}$ «PFFC II» para referirnos a estos dos trabajos.

Conviene señalar que, antes de Los problemas fundamentales, don Ángel ya había hecho una incursión de gran alcance en el campo de los estudios lingüísticos, al prologar y traducir al español los Principes généraux de linguistique indo-européenne (Hachette, París, 1890) de Paul Regnaud (1838-1910). La versión de Amor Ruibal ostentaba el siguiente título: Principios generales de lingüística indo-europea. Versión española, precedida de un estudio sobre la ciencia del lenguaje por el Dr. Á. Amor Ruibal (Consello da Cultura Galega, Santiago de Compostela, 2005 [princeps, 1900]). Nota: a partir de ahora emplearemos las siglas «CL» para referirnos a este trabajo (concretamente, a la «Introducción» que firma Amor Ruibal).

4. A. Domínguez Rey, «El carácter reflejo del lenguaje en Á. Amor Ruibal», en J. Romera, A. Illera e M. García-Page, eds., Semiótica(s): Homenaje a Greimas. Actas del III Seminario Internacional del Instituto de Semiótica Literaria y Teatral (Madrid, UNED, 26-28 de abril, 1993), Universidad Nacional de Enseñanza a Distancia/Visor, Madrid, 1993, p. 191.

Ante la previsible dificultad de acceder al volumen de actas que acoge el trabajo de Domínguez Rey, señalaremos que éste ha sido objeto de una reimpresión (bajo el título de «Carácter reflejo del lenguaje: Á. Amor Ruibal»), en El drama del lenguaje (Universidad Nacional de Enseñanza a Distancia/Verbum, Madrid, 2003; cf. pp. 30-62). 
filosófica, metafísica y teológica nos deja como estábamos. Se citan sus ocupaciones lingüísticas de pasada, como si de curiosidades de aficionado se tratase, y todas las explicaciones o glosas se centran en su «correlacionismo», o en las características que a este cabe asignar, o en lo que dan en llamar algunos su «evolucionismo restringido $»^{5}$. Con todo, tal vez deba aclarar -por si alguien pudiera llevarse a engaño- que la obra lingüística de Amor Ruibal se halla íntimamente ligada a su reflexión filosófica, en trabadísima conexión con ésta. Él mismo nos lo dice y establece análoga exigencia para quien quiera afrontar los problemas propios del estudio del lenguaje con el debido rigor, y a salvo de la recaída en errores tópicos:

Es grave error creer que los estudios filológicos pueden aislarse de los problemas de la Filosofía con la cual están aquellos estrechamente ligados, no sólo por los principios lógicos y psicológicos que forman parte del lenguaje, sino también por los más abstractos de la ontología que son su cimiento y base: la historia de la filología lo confirma plenamente; pues si es verdad, como dice [José M. Gómez de] Hermosilla [1771-1837] (Princip[ios] de Gramática gen[eral] ${ }^{6}$. -Introducción) que «desde Platón acá no ha habido tal vez un sólo filósofo que, poco o mucho, no haya dicho algo de las palabras consideradas como signos de las ideas» ${ }^{7}$, lo es también que no ha habido filólogo que al discurrir sobre las palabras no haya ido a parar a alguna de las teorías por esos filósofos sustentadas ${ }^{8}$.

Y sugiere una propedeútica para el estudio psicológico del lenguaje -en su opinión, el único que hace justicia a su naturaleza- que hoy nos resulta chocante:

5. Una breve introducción a las ideas filosóficas de Ángel Amor Ruibal, donde se presentan algunos de sus conceptos-clave, nos la ofrece, por ejemplo, José Luis Abellán (Historia crítica del pensamiento español. Tomo V: la crisis contemporánea, Madrid, Espasa-Calpe, 1991, pp. 30-45).

6. J. M. Gómez de Hermosilla, Principios de gramática general, Imprenta Real, Madrid, 1835.

7. J. M. Gómez de Hermosilla, Principios..., op. cit., p. VI.

8. CL, p. 57. 
Ya que no nos sea posible ni aún bosquejar una descripción de las leyes del lenguaje psicológicamente considerado[,] séanos permitido recordar aquí (aunque parezca absurdo a muchos filólogos) que sin el meditado estudio de la filosofía clásica en los maestros del escolasticismo, habrán forzosamente de fracasar los mejores intentos en la materia ${ }^{9}$.

Conviene notar que los problemas psicológicos que se ofrecen en la filología, no pueden resolverse sin un conocimiento exacto de los puntos fundamentales de la Ideología, como el del origen y génesis de las ideas, etc. ${ }^{10}$.

Y prosigue, a renglón seguido, con una enumeración de algunas de las cuestiones - la cualidad de las operaciones intelectuales, el orden cronológico de los conceptos o la naturaleza de nuestros juicios- que vendrían a ilustrar la clase de conocimiento que considera ineludible para afrontar con garantías dicho estudio.

Queda clara, pues, la esencial relación que entre ambos dominios, el lingüístico y el filosófico, establece Amor Ruibal. Su idea de noción (y otras tantas de idéntica importancia que no es el caso referir aquí), por ejemplo, cumple un papel muy relevante en sus reflexiones sobre el lenguaje; pero el valor propio que a ellas cabe asignar nos ha de permitir -espero- sin violentar por ello en demasía el espíritu de su pensamiento, aislar o independizar sus obras lingüísticas para un mejor entendimiento. Y eso es lo que aquí emprendemos: una consideración de Amor Ruibal en su vertiente exclusivamente lingüística.

9. CL, p. 59 n. 1. Un par de páginas antes (CL, p. 58 n.) se manifiesta Amor Ruibal contra la ignorancia filosófica entre los lingüistas, que achaca al triunfo de un burdo positivismo: «Cuando vemos a ciertos filólogos (lo mismo pudiera decirse de muchos filósofos) manejar a Platón con desusado afán para sostener sus opiniones lingüísticas, y despreciar luego los problemas de la Ideología, en que apoya Platón sus teorías; estudiar en Aristóteles su modo de pensar sobre estas materias y reirse después de las Categorías del filósofo de Estagira (indispensables en la ciencia del lenguaje) como invención del escolasticismo, siéntese un instintivo movimiento de repulsión hacia tales doctrinas y tales hombres que, como dijo de ellos Maimónides, "han nacido para apalear la ciencia a costa de las fuerzas de los sabios de buena fe que la formaron"».

10. CL, p. 59 n. 1. 


\section{BREVE EXCURSO SOBRE LA RECEPTIVIDAD LINGÜÍSTICA DE AMOR RUIBAL}

Para hacerse cargo de la importancia de nuestro autor, acaso no esté de más referir, siquiera brevemente, algunas de las formulaciones y noticias que cabe encontrar en su obra, que dan cuenta de la puntualidad con que recibía las novedades conceptuales en el campo de la lingüística, de lo al día que se hallaba y de la sutil perspicacia con la que a veces avanzaba más allá de los confines del concepto recogido y asimilado.

En fecha tan temprana como 1900, se refiere, por ejemplo, al Essai de sémantique ${ }^{11}$ de Michel Bréal (1832-1915) ${ }^{12}$, que inaugura la ciencia del significado en su sentido estricto y moderno (el curso posterior de los acontecimientos haría que el enfoque diacrónico que Bréal le dio a esta disciplina en su nacimiento se fuera postergando. Por otra parte, conoce de sobra las contribuciones más importantes a la indoeuropeística de la época, como un examen atento de la bibliografía por él manejada nos puede fácilmente corroborar. Entre dichos textos se halla la famosa Mémoire ${ }^{13}$ de Ferdinand de Saussure $(1847-1913)^{14}$, de cuya revolucionaria propuesta (aunque ya por entonces no tan novedosa) es bien consciente nuestro autor.

En varios pasajes de sus dos grandes trabajos lingüísticos, y en especial para lo tocante a la discusión sobre la validez como construcción teórica de las clasificaciones de las lenguas, nuestro autor cita a William Dwight Whitney (1827-1894) ${ }^{15}$, el gran indianista norteamericano, que anticipa ya algunas de las ideas desarrolladas más tarde por Saussure, y de quien acaso haya que suponer que tomó Amor Ruibal más aspectos de los que su tajante crítica al rechazo de las clasificaciones pudiera hacernos pensar. Don Ángel es también sensible a la introducción de términos de nuevo cuño, como es

11. M. Bréal: Essai de sémantique (science des significations), Hachette, París, $1899^{2}\left[1^{\text {a }}\right.$ edición, 1897].

12. Cf. CL, p. 104 n.

13. F. de Saussure, Mémoire sur le système primitif des voyelles dans les langues indo-européennes, Teubner, Leipzig, 1879.

14. Cf. CL, p. 65 n.

15. Cf., por ejemplo, CL, p. 82 n 1; PFFC I, pp. 41 ss.; PFFC II, p. 135. 
el caso de fonema, vocablo que (aunque acuñado un par de decenios antes), comienza a ganar adeptos a principios del siglo $\mathrm{XX}^{16}$. Y ante todo, a mi entender, llega a anticipar en alguno de sus párrafos la idea de valor, que, como todos ustedes saben, va a resultar decisiva en la lingüística inmediatamente posterior. Así, por ejemplo, en este pasaje, que evocará en sus mentes -espero- las palabras de Saussure según las cuales es propio de los valores el no confundirse nunca con los elementos materiales que les sirven de soporte ${ }^{17}$.

La palabra es la representación menos sensible que puede imaginarse, y por eso responde a todas las demás sensaciones y no puede ser representada por ninguna; es además la representación más simple e incompleja que puede darse, porque responde a una sola sensación y porque es independiente de toda representación concreta, de todo objeto determinado ${ }^{18}$.

No es ésta, empero, la única idea de las formuladas en las páginas de Amor Ruibal que habrá de alcanzar notoriedad en la lingüística del siglo xx. Así, don Ángel avanza (de manera bastante precisa) el concepto de composicionalidad, que él entiende no sólo restringido a la construcción del sentido de la frase (como de común se considera en la semántica formal), sino también atinente a la estructura morfológica de las palabras y de los sintagmas. Establece, además, un procedimiento análogo al de la derivación por reglas en la gramática generativa clásica, al tiempo que postula un principio de estructuración binaria:

16. «De [Franz] Bopp [1791-1867] son la aserción axiomática de la existencia de leyes fijas dentro de las cuales se modela todo sonido, todo fonema, como ahora dicen, y toda palabra; la doctrina de las raíces primitivas, y demás puntos generales de la teoría» (CL, pp. 132-133).

17. «Toutes les valeurs conventionnelles présentent ce caractère de ne pas se confondre avec l'élément tangible qui leur sert de support. Ainsi ce n'est pas le métal d'une pièce de monnaie qui en fixe la valeur; un écu qui vaut nominalement cinq francs ne contient que la moitié de cette somme en argent; il vaudra plus ou moins avec telle ou telle effigie, plus ou moins en deçà et au delà d'une frontière politique» (F. de Saussure, Cours de linguistique générale, Payot, París, 1972 [1ª edición, 1916], p. 164).

18. CL, p. 60. 
La composición de la palabra[,] cualquiera que sea, responde a una idea simple del espíritu, y de ahí las leyes especiales de composición, entre las cuales es la más singular que toda composición procede por pases [sic, por pares], esto es[,] que por múltiple que sea la composición de una palabra ha de descomponerse en elementos pares ${ }^{19}$.

Esta pequeña muestra, espigada de modo un tanto azaroso, sumada a su manejo de la mejor tradición de la gramática alemana del siglo XIX, basta para poder considerar a Amor Ruibal el mejor conocedor y el mayor representante de la lingüística española de aquellos años. Si ello no exigiese una incidencia en el entorno intelectual inmediato de la que, por lo que sabemos, careció, cabría otorgar a Amor Ruibal el título de introductor de la lingüística general en nuestro país. Objetivamente, un siglo después, así se nos aparece al rescatar sus textos del olvido. Su pretensión de hallarse en la línea de sucesión directa de Lorenzo Hervás y Panduro (1735-1809) estaría, pues, plenamente justificada. Pero si atendemos, por contra, al influjo efectivo, al número de discípulos, a la visibilidad de cierto magisterio, habríamos de pasar por él como por sobre ascuas ${ }^{20}$.

\section{TIPOLOGÍA: FUENTES Y PROBLEMAS}

Una vez establecidos el cuadro y el rango de los honores que le corresponden a nuestro autor, me adentro propiamente en el tema de mi conferencia, que ha de ser «Amor Ruibal y la tipología lingüística» y no, como por un desliz se dejó leer en el programa del Simposio, «La tipología lingüística de Amor Ruibal». Mi propósito es hoy más modesto de lo que el entusiasmo y la benevolencia para conmigo les hizo suponer a los organizadores que tan

19. CL, pp. 103-104.

20. Por desgracia, una carta de felicitación de Ramón Menéndez Pidal, fechada a 12 de enero de 1907, en que se saluda con elogio la aparición de Los Problemas Fundamentales de la filología comparada (cf. S. Casas Blanco, «Introducción general», en Á. Amor Ruibal, Los problemas fundamentales de la filosofía y del dogma. [Tomo] I, CSIC: Instituto de Filosofía Luis Vives, 1972, 29 n. 26) no pasa de ser una anécdota a beneficio de inventario, insignificante en cuanto a la incidencia objetiva del trabajo en el ámbito hispánico. 
gentilmente me han invitado. No pretendo aquí reconstruir de veras y en su integridad el pensamiento tipológico de Amor Ruibal en toda la plenitud que a este término quepa darle; no pretendo, no, asignarle a don Ángel una concepción propia al respecto, sino únicamente establecer el lugar que los pensamientos sobre tipología y clasificación de lenguas ocupan en su obra, fijar las fuentes más importantes a las que para tal fin acudió, y comentar algunos aspectos que entiendo especialmente importantes. Todo ello ha de constituir un inexcusable primer paso, si el siguiente (el que benévolamente me asignaban para hoy los organizadores), ha de abordarse con rigor.

A fin de dibujar un panorama lo más claro y amplio posible de la relación de Amor Ruibal con la tipología lingüística, procederé del siguiente modo: en primer lugar, presentaré los escritos y pasajes donde se trata de tales cuestiones; a continuación, habré de referirme a las clasificaciones allí mencionadas; el tercer y último paso me llevará a una breve crítica de fuentes y al análisis de la problemática conceptual que en relación con estas se plantea. Ya anticipo respecto a este tercer punto que tendremos ocasión de comprobar uno de los mayores peligros e inconvenientes que acechan desde siempre (junto a un no desdeñable número de ventajas) a los solitarios y a los pensadores que, por los motivos que fueren, se han visto recluidos, o reducidos, a un aislamiento más o menos espléndido, a saber: el de volverse en gran medida dependientes de los libros recibidos, sobrevalorando a veces aspectos de cierta obra caída en sus manos en el momento oportuno, y desestimando otras ideas de mayor importancia que acaso, de modo paralelo, se hayan sugerido sobre el mismo punto. Las más de las veces, tales fenómenos se explican con referencia a los volúmenes de su biblioteca; a menudo, el filón más provechoso para el desarrollo de una idea (o para evitar al menos la caída en un tratamiento menos fructífero o en una interpretación sesgada o errónea en un aspecto de la máxima importancia), lo habría proporcionado un autor manejado con soltura, que, sin embargo, pasó inadvertido en relación al punto crítico. Ello sucede con notable 
frecuencia (y es no sólo perfectamente comprensible, sino también disculpable) cuando quien escribe ha de procurarse él mismo el cobijo entero de una tradición, crear con sus lecturas el ámbito que de diario le falta. Creo, si se me permite decirlo, que la mayor parte de los malentendidos o confusiones de importancia en cuanto a tipología que encontramos en las páginas de Amor Ruibal provienen de que, por un lado, no conocía de primera mano la obra de Wilhelm von Humboldt (1767-1835) y de que, por otro lado, se basaba para la interpretación de las ideas del gran lingüista prusiano en la lectura que de él hace Max Schasler (1819-1903) ${ }^{21}$, antes que en el bastante más fiable Heymann Steinthal (1823-1899).

\subsection{Los textos de Amor Ruibal sobre tipología}

Preguntémonos, antes de nada: ¿de qué textos cabe extraer las ideas de Amor Ruibal sobre tipología lingüística o, mejor dicho -para mantener la modestia declarada de nuestro propósito meramente preliminar-, su exposición de las ideas tipológicas de cuño corriente en la investigación lingüística de la época? En primer lugar, de su largo prólogo a la traducción de los Principes de Paul Regnaud; en segundo lugar, de algunos capítulos de Los problemas fundamentales de la filología comparada. La prioridad de la «Introducción» a la obra de Regnaud no es sólo cronológica ${ }^{23}$, sino también conceptual. En efecto, a pesar de la monumentalidad de Los problemas fundamentales, de la abrumadora erudición con que allí se nos obsequia, del detenido seguimiento que en capítulos enteros se hace del desarrollo del pensamiento sobre el lenguaje en las más variadas épocas y pueblos, a pesar -digo- de todo ello,

21. M. Schasler, Die Elemente der philosophischen Sprachwissenschaft Wilhelm von Humboldt's, aus seinem Werke: "Über die Verschiedenheit des menschlichen Sprachbaues und ihren Einfluss auf die geistige Entwicklung des Menschengeschlechts», Trautwein'schen Buch- und Musikalienhandlung, Berlín, 1847.

22. Sobre todo, el capítulo VII de la Segunda parte (PFFC II, pp. 371-467), que lleva el título de «Las clasificaciones glotológicas»; en menor medida, también el IX, «Las fases glotológicas» (PFFC II, pp. 587-646), donde expone la teoría de los tipos fijos y la de fases, a semejanza esta última de la de los tres estados de la física).

23. Cf. supra n. 3. 
dicha obra, en lo referido a ideas sobre tipología lingüística y propuestas de clasificación estructural de las lenguas del mundo, es, ante todo, una extensión de lo ya expuesto en 1900. Numerosos párrafos (y esto no atañe sólo a los capítulos que aquí nos interesan) se repiten en forma casi idéntica. Lo esencial, a mi entender, se encuentra ya en la primera de las dos obras aquí mencionadas: conceptualmente, los capítulos VII y IX de Los problemas fundamentales son una prolongación de lo que ya hallamos en la «Introducción». Con todo, la enumeración detallada de las clasificaciones propuestas en el marco de la tradición decimonónica (con los correspondientes cuadros sinópticos o tablas taxonómicas), sólo se hará explícita en 1905. Por mi parte, me referiré por igual a ambas obras a lo largo de esta exposición.

\subsection{Las clasificaciones lingüisticas en Amor Ruibal}

¿Cuáles son esas clasificaciones que nuestro autor cita y maneja, que recoge de los múltiples libros que le llegan a su rincón compostelano, este mismo rincón desde el que hoy lo rememoramos? Don Ángel se refiere, en algunos casos repetidamente, y por este orden, a las clasificaciones de Friedrich von Schlegel (17721829), de August Wilhelm von Schlegel (1767-1845), de Friedrich Müller (1834-1898), de Franz Bopp (1791-1867), de Wilhelm von Humboldt, de F. Max Müller (1823-1901), de August Schleicher (1821-1868) y de August Friedrich Pott (1802-1887). Menciona también, en muchísima menor medida (sólo en unas breves líneas a pie de página, con el manifiesto propósito de someterlas a severa crítica) las propuestas de Daniel G. Brinton (1837-1899), de Jules Oppert (1825-1905), de Raoul de la Grasserie (1839-1914) y de Ruggiero Bonghi (1826-1895) ${ }^{24}$. La simple enumeración produce

24. PFFC II, p. 380 n. 1. En comparación con cualquiera de los ocho anteriores, estos cuatro estudiosos son figuras de segunda fila. Acaso cabría hacer una excepción con Oppert, que desarrolló una exitosa carrera en el ámbito de la asiriología, convirtiéndose en el titular de la primera cátedra que de dicha materia se creó en Francia (cf. G. Conteanu: «L'assyriologie», en VV. AA., Société Asiatique. Le livre du centenaire (1822-1922), Geuthner, París, 1922, pp. 94-96). Los tres autores restantes eran, en rigor, aficionados entusiastas, dicho sea sin ánimo de menospreciarlos. El estadounidense 
vértigo. Los más de estos autores son gigantes de la filología comparada y de la lingüística del siglo xIx. Con todo, resulta llamativo que, a pesar de haberle dedicado algunas páginas en su recorrido por la historia de la filología ${ }^{25}$, se olvide de la propuesta de Johann Chr. Adelung (1732-1806) en el Mithridates ${ }^{26}$, siendo como es la primera partición tipológica de las lenguas de que parece existir noticia (es, al menos, la primera atestiguada en el ámbito alemán, del que se nutre Amor Ruibal principalmente).

La presentación de las propuestas clasificatorias viene precedida y acompañada en Amor Ruibal de importantes considera-

Brinton, médico, esbozó una clasificación de las lenguas indígenas de América que se basaba principalmente en la comparación de sus estructuras gramaticales (acerca de su obra lingüística y antropológica, cf., por ejemplo, J. T. Andresen, Linguistics in America, 1769-1924, Routledge, Londres/Nueva York, pp. 197-205). El francés De la Grasserie, juez, se adentró en cuantos temas y problemas de lingüística general se le ofrecían a la vista; por desgracia, su desmedido amor por la investigación (unido a lo apresurado de sus lecturas) lo condujo a cometer algunos errores de importancia (cf., por ejemplo, A. Meillet, "[Compte-rendu de] Raoul de la Grasserie, Essai d’une sémantique intégrale», Bulletin de la Société de Linguistique de Paris, XVI/57, 1910, pp. LXIV-LXV). Bonghi, en fin, fue un fecundo publicista italiano que llegó a ocupar, entre otros cargos de gran relieve, el de Ministro della Pubblica Istruzione (1874-1876). En medio de sus numerosas ocupaciones, pudo reunir el tiempo necesario para idear una propuesta de clasificación de las lenguas -hoy olvidada- «in base all'esistenza, o meno, del verbo in esse, e del grado di esistenza» (G. de Gregorio, Glottologia, Hoepli, Milán, 1896, p. 227).

25. PFFC II, pp. 8 ss.

26. J. Chr. Adelung [y J. S. Vater], Mithridates, oder allgemeine Sprachenkunde, mit dem Vater Unser als Sprachprobe in bey nahe fünf hundert Sprachen und Mundarten, Vossischen Buchhandlung, Berlín, 4 vols., 1806-1817.

Como es sabido, la obra de Adelung se sitúa -desde el título mismo- en la estela del proyecto de Konrad Gesner (1516-1565), que había intentado dar noticia de todas las lenguas conocidas en su Mithridates, sive de differentiis linguarum tum veterum, tum quae hodie apud diversas nationes in toto orbe terraru $[\mathrm{m}]$ in usu sunt ([Johannes] Froschoverus, Tiguri [i. e., Zúrich], 1555). En la introducción al primer volumen («Einleitung. Fragmente über die Bildung und Ausbildung der Sprache», en J. Chr. Adelung, Mithridates, oder.., op. cit., vol. 1, pp. IX ss.), Adelung establece una clasificación bipartita de las lenguas: a su parecer, éstas pueden ser, bien «einsylbige» ('monosilábicas'), bien «mehrsylbige» ('polisilábicas'). Por supuesto, Adelung está persuadido de la superioridad de las lenguas polisilábicas, clase a la que pertenecen las grandes lenguas de cultura del Occidente (aunque no sólo éstas). Hasta tal punto lo está, que da a uno de los apartados de la introducción el expresivo título de «Vortheile der Mehrsylbigkeit» («Einleitung. Fragmente...», op. cit., pp. XXXII-XXXIII). 
ciones teóricas. Antes de pasar al análisis de las ideas tipológicas específicas de cada autor, Amor Ruibal aborda el problema in abstracto. Frente a Whitney, que juzgaba inviable la clasificación de las lenguas stricto sensu por violentar la individualidad radical de cada sistema lingüístico, y criticaba muy en particular los intentos de clasificación morfológica ${ }^{27}$, nuestro autor considera legítimo el propósito clasificador, y lo justifica metodológicamente:

En punto a las relaciones del lenguaje con la etnografía (en orden a clasificaciones lingüísticas), debemos decir: a) que pueden hacerse tantas clasificaciones en los idiomas, cuantos son los diversos puntos de vista desde donde podemos considerarlos, y los distintos grados que dentro de las clasificaciones existentes pueden determinarse; b) todas las clasificaciones son relativamente nuevas (las más antiguas son las de Schlegel y Humboldt), y ninguna de las existentes es admitida por todos de un modo indiscutible, aunque no siempre concuerden las razones de discrepancia ${ }^{28}$.

A continuación, Amor Ruibal procede, en el mismo párrafo de las líneas precedentes, a enumerar las razones por las cuales ninguna clasificación de las lenguas puede pretender para sí validez absoluta. Su modo de argumentar deja entrever un posible modelo triádico del lenguaje, sobre el que nuestro autor acaso estuviera meditando durante aquellos años. De ser así, no sólo habría anticipado algunas de las ideas de Saussure, sino que se hallaría próximo a las concepciones de Charles S. Peirce (1839-1914) sobre firstness, secondness y thirdness:

27. Aunque le concede cierta utilidad práctica, Whitney compara la clasificación morfológica con una clasificación botánica que se fundase sólo «on the number of stamens or the combination of leaves», pasando por alto o desdibujando «other distinctions of equal or of greater importance» (The life and growth of language, Appleton, Nova York, 1875, p. 277; cf. CL, p. 83 n. 1). Amor Ruibal (cf. PFFC II, p. 381) le reprocha a Whitney que elabore su impugnación a partir de un falso supuesto, sin el cual todo su argumento carece de valor, a saber: la creencia de que la genealogía de las lenguas sea diferente de su morfología.

28. CL, p. 78. 
Ninguna de ellas [las clasificaciones lingüísticas] puede presentarse como tipo absolutamente fijo en la materia, por la razón general absoluta de que no miran las lenguas bajo todos sus aspectos ni se conoce la categoría de las que hayan desaparecido; por la razón general relativa de que no es determinable la naturaleza de muchos idiomas con relación a grupos definidos en sus múltiples aspectos; y por la razón particular de que no todos convienen en fijar el concepto de flexión y de aglutinación, sin lo cual deben necesariamente existir clasificaciones discrepantes ${ }^{29}$.

Tras establecer que las clasificaciones lingüísticas se reducen a cuatro («morfológica», o «por razón de la estructura», «psicológica», o «por razón de la aptitud para expresar los conceptos», «genealógica», o «por razón del origen de los idiomas», y «etnográfica», que forma «los tres grandes grupos de lenguas indo-germánicas, semíticas y tártaras» $\aleph^{30}$ ), pasa Amor Ruibal a discutir la jerarquía o rango relativo que cabe fijar entre ellas, otorgando prelación a las clasificaciones de naturaleza genealógica, como no podía ser menos tratándose de un comparatista ${ }^{31}$ :

De todas estas clasificaciones, la etnográfica es la menos científica, aunque práctica; la genealógica es, como dice Max Müller, la más perfecta desde el punto de vista filológico, pero la de más difícil aplicación, porque se desconoce la naturaleza de muchos idiomas y se ignoran lenguas madres tal vez desaparecidas; la psicológica (cuya división fundamental es en lenguas con formas y sin formas) es desde

29. CL, p. 78.

30. CL, p. 78. En otros pasajes de sus trabajos lingüísticos, Amor Ruibal menciona un quinto tipo de clasificación: la «geográfica» (cf., por ejemplo, PFFC II, p. 373).

31. No creo que se pueda dudar ni por un instante de la fidelidad de Amor Ruibal al método histórico-comparativo en lo que hace a la investigación lingüística. La glotología general que trataba de fundamentar no debía abandonar, en la generalidad de sus conceptos, el suelo que habían roturado con su paciente quehacer los grandes autores de la filología alemana del siglo xix. Para Amor Ruibal la lingüística general comienza por ser filología comparada. Y, por más que avance a fuerza de tratar de ser otras muchas cosas (teoría de la génesis de los conceptos o ideología, lingüística psicológica o de la relación entre el lenguaje y los procesos del pensar, etc.), no le es dado contradecir su carácter primero y primordial. 
el punto de vista ideológico la más perfecta, pero ocasionada a confusiones en la ejecución, como efectivamente se echa de ver en las clasificaciones de este género. La clasificación más asequible y la comúnmente admitida es la morfológica ${ }^{32}$.

Cuando se atiende a las propuestas de clasificación morfológica y a los conceptos que se encuentran en su base se descubre, según nota Amor Ruibal con notoria perspicacia, que gran parte de los malentendidos y de las contradicciones observadas se dejan retrotraer a un problema conceptual de partida, a saber: qué ha de entenderse bajo el término flexión o bajo el de aglutinación con el que aquél linda:

Dentro de la clasificación morfológica existen diversos criterios y apreciaciones diversas en la distribución de idiomas, las cuales en buena parte son debidas a la multitud de opiniones y pareceres sobre la naturaleza de la flexión. Es este punto capital que desde los comienzos de esta suerte de clasificaciones, cualquiera habría juzgado perfectamente aclarado y definido, ya que sin él toda distribución morfológica de idiomas será siempre subjetiva y convencional; y es sin duda por eso mismo que los filólogos, dando por prestablecida y determinada la noción de las flexiones, pasan a clasificar los idiomas, sin advertir que ni los cuadros lingüísticos que ellos fijan o aceptan, ni los que critican en los demás, pueden ser sostenidos o desechados sin declarar primero la naturaleza filológica de la flexión y aglutinación ${ }^{33}$.

A pesar de considerar la flexión como uno de los primitivos con que ha de contar toda clasificación morfológica de las lenguas, Amor Ruibal llama la atención sobre el hecho de que dicha idea es internamente compleja:

Y es que, contra lo que implícitamente se supone en la vaga noción de lenguas flexivas, la flexión no es concepto simple, sino harto complejo que nace por oposición a las formas históricas de las lenguas dichas aglutinantes, y que comprende toda manera de alteración fonética que expresa una modificación semántica en los idiomas cuyo tipo mor-

32. CL, pp. 78-79.

33. CL, p. 79. 
fológico ofrece unidades gramaticales reducibles por análisis a elementos simples real o idénticamente distintos entre sí. De aquí que la flexión, como hemos indicado, pueda consistir ora en la modificación del radical o de la raíz bajo la influencia de la desinencia o de los sufijos, ora en la modificación de los sufijos al eslabonarse a la palabra raíz, ora en las alternaciones vocales que con carácter significativo experimentan frecuentemente las voces en su juego morfológico. Entendida, pues, la flexión en la manera corriente de modo que no incluya todos estos fenómenos fonéticos, es forzosamente erróneo el concepto de ella, y ocasionado a inexactitudes por demás frecuentes y comunes en los tratados glotológicos; y esta es también la causa de que con incoherencia manifiesta, según unos, las lenguas semíticas deben decirse flexivas excluyendo las indoeuropeas, y, según otros, a la inversa, sean flexivas las indoeuropeas y no las semíticas ${ }^{34}$.

34. PFFC II, p. 393. En Amor Ruibal la complejidad de la flexión se entiende por remisión a su génesis. Al mismo tiempo se trata de la complejidad propia de un concepto interiormente articulado y diferenciado. En lo referente a su génesis, hay algo llamativo en cómo Amor Ruibal traza el problema. Admitido el hecho de las formas históricas de las lenguas aglutinantes tal y como les fue dado observarlas a los filólogos de comienzos del siglo xIX, y desgajado de este puro dato el concepto mismo de aglutinación, no procede Amor Ruibal -como tal vez cupiera esperar por su bagaje escolástico- por un transitum ab intellectu ad rem conducente a caracterizar el fenómeno inmediato de las lenguas flexivas desde el concepto de aglutinación en un verdadero saltus mentis. Más bien, parece entender el concepto -en este caso particular, el de flexión- como una suerte de organismo que, mediante una serie de mecanismos de regulación, se defendiese de las agresiones -por así decirlo- de los conceptos limítrofes o circundantes. A partir de cierto sustrato empírico (las diferentes lenguas catalogadas de flexivas, y amenazadas en parte, por indeterminación, de subsunción bajo la idea de aglutinación) se produciría una génesis automórfica del concepto. De tener razón en la interpretación que aventuramos, habría que ver en Amor Ruibal a un monista convencido del isomorfismo -estructural y ontológico- entre las formas del mundo fenoménico y las estructuras subyacentes de nuestra cognición. Su correlacionismo no sería sino otro nombre con que referirse a dicha analogía.

Por lo demás, y para que el lector pueda contextualizar la postura de Amor Ruibal, voy a reproducir seguidamente unas líneas donde se rememoran algunas de las principales actitudes que los lingüistas del siglo xIX adoptaron ante el difícil problema de las relaciones entre flexión y aglutinación: «Bopp -apunta Brigit Beneš (Wilhelm von Humboldt, Jacob Grimm, August Schleicher: ein Vergleich ihrer Sprachauffassungen, Winterthur, Keller, 1958, p. 30)- hatte die ganze Flexion des Sanskrit aus Agglutination erklärt; die Konjugation aus agglutinierten Personalpronomina und Hilfsverben, die Deklination aus verschmolzenen Prepositionen. Friedrich Schlegel 
Así pues, se puede decir -sin demasiado esfuerzo imaginativo y siendo fieles en lo esencial a las palabras del pasaje precedente-, que Amor Ruibal comprende bajo el término flexión los fenómenos de Ablaut, las reglas sandhi atinentes a los límites morfológicos en el interior de una palabra, y algunos tipos, cuando menos, de armonía vocálica.

A renglón seguido, pasa nuestro autor a enumerar los tres «grados» o «categorías» de flexión que cabe establecer:

Puede considerarse como primer grado o categoría flexiva la modificación de la raíz o del radical bajo la respectiva influencia de los sufijos y de la desinencia, en el cual grado mejor que las lenguas

dagegen, dessen Partei sein Bruder ergriff, hatte Agglutination und Flexion als absolute Gegensätze aufgefasst und die Sprachen danach in mechanische und organische eingeteilt, wobei er die Flexion als organische Entfaltung aus der Würzel erklärte. Humboldts Stellungnahme $\mathrm{zu}$ diesem Problem, das die ganze frühe Sprachwissenschaft beschäftigte, ist sehr charakteristisch: von Friedrich Schlegels mystizistischer organischer Entfaltung wollte er nichts wissen, noch weniger von dessen prinzipieller Unterscheidung zwischen mechanischen und organischen Sprachen: So hat es mir daher schon längst geschienen, dass jede Sprache aus einem ungeformt gebliebenen und einem durchaus geformten Teile zusammengesetzt ist. Zwischen Agglutination und Flexion sah Humboldt keinen absoluten Gegensatz, sondern nur einen verschiedenen Grad von Formalität, welche auch in den historischen Flexionsprachen nicht vollkommen durchgedrungen war».

En cuanto a la adscripción de las lenguas semíticas a un tipo u otro, constituye uno de los problemas más discutidos entre los lingüistas del siglo xIX. Así, Bopp se inclinaba a incluir las lenguas indoeuropeas bajo las aglutinantes, al tiempo que adscribía las semíticas a un tipo especial caracterizado por la modificación interna de la raíz por medio de la mutación de las vocales de la raíz, o, como él dice, «durch blosse innere Modification der Wurzeln» (Vergleichende Grammatik des Sanskrit, Zend, Griechischen, Lateinischen, Litthauischen, Gothischen und Deutschen, Dümmler, Berlín, 1833, pp., 113). Friedrich von Schlegel, por su parte (cf. Über die Sprache und Weisheit der Indier. Ein Beitrag zur Begrundung der Alterthumskunde, Mohr und Zimmer, Heidelberg, 1808, p. 49), se había decidido a considerar las lenguas de la familia semítica entre las aglutinantes. Suscitó así, como nos recuerda Amor Ruibal (CL, p. 80 n. 2), una feroz crítica de Friedrich Müller: «Doch scheint F. v. Schlegel von der Flexion einen anderen Begriff sich gebildet zu haben, als er der heut zu Tage unter den Sprachforschern geltende ist, da er sonst nicht die semitischen Sprachen zu den agglutinirenden rechnen würde» (Grundriss der Sprachwissenschaft. Band I. Einleitung in die Sprachwissenschaft, Holder, Viena, 1876, p. 66). 
semíticas pueden comprenderse, aunque no de un modo completo, las lenguas indo-europeas. El segundo grado resulta de las modificaciones de los sufijos por su enlace con la palabra-raíz, en el cual grado son plenamente flexivas las lenguas indo-europeas. En ambos grados mencionados trátase, como se ve, de los casos de verdadera aglutinación en las lenguas flexivas. El tercer grado de flexión está constituido por la alteración y permutación vocal en las palabras con efectos significativos. En este grado son plenamente flexivas las lenguas semíticas, y también, aunque esto no sea su característica, las lenguas indo-europeas, según veremos. Esta categoría flexiva es independiente de toda aglutinación, y puede hallarse lo mismo en formas aglutinadas que en formas simples, revelándose no sólo por esto superior a los grados anteriores, sino también por su carácter más íntimo a la palabra modificable ${ }^{35}$.

Basten los párrafos precedentes por lo que toca a las consideraciones metodológicas que don Ángel vierte como preámbulo a las propuestas clasificadoras que se propone referir y comentar, y que a veces nos presenta como una coda o bordón a éstas. Cumple entonces que atendamos, a continuación, a las fuentes a las cuales remite Amor Ruibal, a los autores que consulta y en los que se basa para elaborar su propia concepción de la tipología lingüística y de las clasificaciones glotológicas.

35. PFFC II, pp. 393-394. Esta categorización de la flexión en tres grados y, más en particular, el establecimiento de un contraste entre las dos primeras acepciones del concepto y la tercera de sus formas permite a Amor Ruibal pronunciarse sobre el carácter último que, en su opinión, ha de atribuirse a las lenguas semíticas: «He aquí por qué, agrupando las dos formas primeras de flexión separadamente de la última, creemos debe distinguirse una categoría de lenguas con flexión aglutinante, más propia del tipo ario que del semítico, y otra de lenguas con inflexión vocal o inflexivas, más propia del tipo semítico que del tipo ario, que constituye la forma más alta flexiva, al par que la más originaria y primitiva» (PFFC II, p. 394). Las elucubraciones de Amor Ruibal sobre la suprema dignidad de las lenguas semíticas -como cuando se refiere a «la superioridad flexiva del tipo semítico sobre el tipo regular histórico en las lenguas arias, lo cual hace más lógico traer las lenguas arias a parangón con las semíticas, que no llevar las semíticas a las arias» (PFFC II, p. 394 n. 1) - y su interpretación glotogónica de los diversos tipos se cuentan entre las páginas más inactuales (vale decir, periclitadas) de su pensamiento lingüístico, y constituyen una magnífica muestra de la cumplida deuda que todo autor ha de pagarle a la época en que le ha tocado vivir. 


\subsection{Las fuentes de Amor Ruibal sobre tipología}

Debemos abordar ahora el delicado punto de la fidelidad con que Amor Ruibal refiere las diversas propuestas clasificatorias. Para ello nos fijaremos en sus menciones a los autores más importantes -menciones que a veces adoptan la forma de la cita directa y más o menos literal, en tanto que otras veces constituyen paráfrasis indirectas en las que no faltan dosis de interpretación por su partey calibraremos en qué medida se ciñen a la formulación original o se apartan de ella. Pero antes, para que dicho repaso (por sumario que sea) resulte valioso, hemos de dedicar algunos párrafos a dilucidar el triple sentido en que cabe entender la tipología lingüística a partir de las reflexiones de Wilhelm von Humboldt. Sólo considerando las diversas acepciones y vertientes de la tarea tipológica podrá ubicarse con justicia la reflexión de Amor Ruibal al respecto.

Cuando nos las habemos con Wilhelm von Humboldt y su aportación a la tipología (como a otros muchos asuntos lingüísti$\left.\cos ^{36}\right)$, la situación es harto complicada. Es el nudo del problema, y no ya en referencia a Amor Ruibal, sino -puede argumentarse- a cualquier autor (también actual) que se pronuncie sobre tipología y clasificaciones morfológicas. Para presentar con la mayor brevedad y precisión sus ideas sobre tipología recurriré a un magnífico artículo que hace años publicó Eugenio Coseriu (1921-2002) ${ }^{37}$, y del que, por desgracia, como he podido atestiguar repetidamente, no se tiene noticia tan exacta y extendida en la comunidad de lingüistas como su importancia exigiría.

36. No en vano Steinthal, rendido admirador suyo, pudo afirmar lo siguiente: «Wir können, wir dürfen keinen sprachwissenschaftlichen Gegenstand untersuchen, ohne sogleich zu fragen, was hat Wilhelm von Humboldt über ihn gelehrt?» (Die Entwicklung der Schrift. Nebst einem offenem Sendschreiben an Herrn Prof. Pott, Dümmler, Berlín, 1852, p. 31). Dado que el volumen de 1852 es inencontrable entre nosotros, no estará de más advertir que se puede hallar una reproducción fascimilar del texto en H. Steinthal, Kleine Sprachtheoretische Schriften, Georg Olms, Hildesheim, 1970, pp. 139-247.

37. «Sobre la tipología lingüística de Wilhelm von Humboldt» [original en alemán, 1972; traducción al español por M. Martínez Hernández], en E. Coseriu, Tradición y novedad en la ciencia del lenguaje. Estudios de historia de la lingüística, Gredos, Madrid, 1977, pp. 142-184. 
En Humboldt no cabe encontrar -y nunca se ha de insistir lo bastante en esto- ninguna clasificación o cuadro de las lenguas del mundo, ni pretensión alguna de afrontar tal tarea. Es más, como bien se encarga de recordarnos Coseriu, tal clasificación es abiertamente contraria a la concepción general del lenguaje de Humboldt, por razones tanto empíricas como conceptuales en las que, desgraciadamente, no nos podemos detener aquí. Humboldt aporta a la clasificación tipológica en lenguas aislantes, aglutinantes, flexivas (y, a veces, incorporantes) que todos hemos recibido, de un modo u otro, en nuestra formación filológica o lingüística, sólo la terminología. Y ello por un peculiar tránsito del intelecto o el nombre a la cosa. En realidad, esa clasificación (entendida además como ampliación de la originariamente propuesta por August Wilhelm von Schlegel) se le debe a Pott. En las consideraciones finales de su artículo, a modo de resumen, advierte Coseriu: «Humboldt no ha adoptado como tal la clasificación de A. W. Schlegel y, naturalmente, tampoco la ha ampliado. Y no solamente no ha establecido una clasificación de las lenguas en cuatro clases, sino que la ha rechazado expresamente» ${ }^{38}$.

Como es obvio, no nos es posible aquí recorrer por entero el camino que ha conducido a asignarle torcidamente a Humboldt una doctrina que en ninguna de sus páginas se halla. Sí nos importa saber, sin embargo, qué fue entonces lo que verdaderamente dijo Humboldt sobre la tipología. Solo así podremos determinar qué grado de comprensión de las verdaderas ideas humboldtianas cabe asignarle a Amor Ruibal. Pues bien, en la obra lingüística de Humboldt $-\mathrm{y}$ sigue siendo Coseriu quien nos ilumina ${ }^{39}$ - cabe reconocer tres acepciones principales de tipología, que se corresponden con sendas direcciones posibles de investigación. De estas tres direcciones, sólo una contiene un aspecto clasificatorio, pero -y esto no cabe olvidarlo- no es reducible a él.

La primera dirección se fundamentaría en la idea del Typus o Sprachbau como innere Sprachform ('forma interior de la lengua'),

38. E. Coseriu, «Sobre la tipología...», op. cit., p. 183.

39. Cf. E. Coseriu, «Sobre la tipología...», op. cit., pp. 161 ss. 
como un principio de estructuración que atraviesa todos los componentes de una lengua. En segundo término, tenemos un enfoque del tipo, no como clase de lenguas, sino como forma ideal y coherente de estructuración lingüística. Es en relación con este sentido de tipo cuando surge en Humboldt la célebre nomenclatura tripartita: Flexion, Agglutination e Isolierung ${ }^{40}$. En este punto, es de la mayor relevancia advertir que tales etiquetas -frente a lo que la interpretación tradicional ha querido siempre ver- no se refieren en Humboldt a las lenguas, sino a procedimientos o mecanismos de estructuración: Verfahren, los llama Humboldt ${ }^{41}$.

40. Hasta donde sabemos, las etiquetas Isolierung y Agglutination no se documentan con anterioridad a Humboldt, con lo cual se suele suponer que son invenciones o acuñaciones suyas. Bien es verdad que a menudo las trata con la distancia que uno suele otorgarle a lo ajeno, o, por lo menos, se expresa de tal suerte que parece estar limitándose a evocar una nomenclatura que estaba en uso de antemano. Cf., por ejemplo, el siguiente pasaje de su obra cumbre, Über die Verschiedenheit des menschlichen Sprachbaues und ihren Einfluss auf die geistige Entwicklung des Menschengeschlechts (Königlichen Akademie der Wissenschaften, Berlín, 1836): «Die hier wirksame oder hemmende Eigenschaft der Sprachen ist nämlicht die, welche man unter den Ausdrücken: Isolirung der Wörter, Flexion und Agglutination zusammenzubegreifen pflegt» (W. von Humboldt, Über die Verschiedenheit..., op. cit., p. 119; cursivas añadidas).

41. Valgan como ejemplo las siguientes líneas: «Das Wort lässt nur auf zwei Wegen eine Umgestaltung zu: durch innere Veränderung oder äusseren Zuwachs. Beide sind unmölich, wo die Sprache alle Wörter starr in ihre Wurzelform, ohne Möglichkeit äusseren Zuwachses, einschliessts, und auch in ihren Inneren keiner Veränderung Raum giebt. Wo dagegen innere Veränderung möglich ist, und sogar durch den Wortbau befördet wird, ist die Unterschiedung der Andeutung von der Bezeichnung, um diese Ausdrücke festzuhalten, auf diesem Wege leicht und unfehlbar. Denn die in diesem Verfahren liegende Absicht, dem Worte seine Identität zu erhalten, und dasselbe doch als verschieden gestaltet zu zeigen, wird am besten durch die innere Umänderung erreicht» (W. von Humboldt, Über die Verschiedenheit..., op. cit., p. 123; cursivas añadidas).

En otras ocasiones, como nos recuerda Coseriu («Sobre la tipología...», op. cit., p. 170), Humboldt utiliza la palabra Methoden (cf., por ejemplo, Über die Verschiedenheit..., op. cit., p. 164). Y tampoco son raras las ocasiones en que se sirve de Mittel; valgan como ejemplo las siguientes líneas: «Dies geht sehr klar aus der Aufzählung der Mittel hervor, welche die Sprache zur Bezeichnung dieser Formen besitzt. Denn diese Mittel bestehen in folgenden: [1] Anfügung, oder Einschaltung bedeutsamer Sylben, die sonst eigne Wörter ausgemacht haben, oder noch ausmachen, [2] Anfügung, oder Einschaltung bedeutungsloser Buchstaben, oder Sylben, bloss zum Zweck der Andeutung der grammatischen Verhältnisse, [3] Umwandlung der Vocale durch Uebergang eines in den 
En el ámbito de los procedimientos, o Verfahren, establece Humboldt una ulterior partición, conforme se refieran al nivel de la palabra (a la constitución de la palabra) o al engarce con la oración (a la articulación de la oración, esto es, al modo de articularse la palabra en la oración $)^{42}$. En cada uno de los casos tenemos una distinción en otros tres procedimientos, como de seguido mostraremos. Resulta, empero, de suma importancia hacer notar que estas particiones las efectúa Humboldt en el interior de una de las formas ideales de estructuración que ha sugerido, de aquella que él estima la forma más acabada y perfecta. Esa división de los Verfahren en niveles la lleva a cabo Humboldt en relación con la flexión, con la forma flexiva de la lengua. No se ha de perder de vista este detalle capital.

Los tres procedimientos que se refieren a la palabra tienen por base, además, un doble plano funcional de esta. De un lado, la palabra como Bezeichnung, esto es, como designación de un concepto; de otro lado, la palabra como Andeutung, esto es, como determinación o inclusión del concepto en una categoría concreta del pensar o del hablar ${ }^{43}$. No podemos dejar de referir en este punto el hecho de que Amor Ruibal no ignora, a la hora de trazar sus clasificaciones, el plano de diferenciación Bezeichnung/Andeutung. Menciona los procedimientos, pero obvia su fondo, dado que se limita al nivel de la palabra. Nada nos dice, pues, sobre los Verfahren humboldtianos de la articulación oracional. Más adelante tendremos ocasión de comentar con algún detalle este hecho.

Volviendo a Humboldt, el equilibrio que la palabra ha de lograr para, por una parte, mantener su unidad designadora (para ser estructuralmente estable, si nos avenimos a usar un concepto matemático del cual la investigación lingüística podría sacar enorme

andern, oder durch Veränderung der Quantität, oder Betonung, [4] Umänderung von Consonanten im Innern des Worts, [5] Stellung der von einander abhängigen Wörter nach unveränderlichen Gesetzen, [6] Sylbenwiederholung» («Ueber das Entstehen der grammatischen Formen, und ihren Einfluss auf die Ideenentwicklung», en W. von Humboldt, Gesammelte Werke. Dritter Band, Reimer, Berlín, 1843, pp. 282-283).

42. Cf. E. Coseriu, «Sobre la tipología...», op. cit., p. 166.

43. Cf., por ejemplo, W. von Humboldt, Über die Verschiedenheit.., op. cit., p. 123. 
provecho) y, por otra parte, señalar la Andeutung (dejarse determinar en el habla y en el pensamiento), sólo le deja a aquélla dos salidas: o la palabra renuncia a dar expresión material a la Andeutung ${ }^{44}$, o bien se decide por expresarla. De encontrarnos ante este segundo caso, debemos introducir un ulterior refinamiento: la expresión de la Andeutung puede consistir en un äusseren Zuwachs ('adición externa') o bien en una innere Veränderung ('modificación interna') ${ }^{45}$. A su vez, el äusseren Zuwachs puede resolverse en Anfügung ('atracción', 'adjunción' o 'aglutinación'), o en un aumento orgánico, al que se le da el nombre de Anbildung ${ }^{46}$.

En este punto, interesa detenerse a señalar que Amor Ruibal es plenamente conocedor de la terminología o nomenclatura de los diversos modos de expresión de la Andeutung, como puede comprobarse por este pasaje en el que, acudiendo a la exposición de Schasler, resume las ideas de Humboldt sobre el particular:

En orden a la flexión, según Max Schasler, distingue Humboldt tres grados lingüísticos: el de simple yuxtaposición a la raíz de un elemento que conserva íntegra su significación (Anfügung), el de sufija-

44. En tal caso, se adopta el procedimiento denominado Isoli[e]rung (cf. supra n. 38), al que Humboldt no le prestará posteriormente atención.

45. Cf. supra n. 39.

46. Cf., por ejemplo, W. von Humboldt, Über die Verschiedenheit..., op. cit., pp. 123-125. En la versión española de la obra, se traduce el término Anbildung por «afijación» (cf. W. von Humboldt, Sobre la diversidad de estructura del lenguaje humano y su influencia sobre el desarrollo espiritual de la humanidad, Anthropos, Barcelona, 1990 [original en alemán, 1836; traducción al español por A. Agud], pp. 148-150). Decisión ésta que queda plenamente justificada al examinar el contexto de la primera aparición de Anbildung: "Geschicht dies, so entsteht, ausser der inneren Veränderung [...], eine [andere] Umgestaltung der Wörter, durch Anbildung, und wir haben alsdann den wahren Begriff eines Suffixes» (Über die Verschiedenheit..., op. cit., p. 124; cursivas añadidas). Quede claro, eso sí, que, para Humboldt, los afijos son incrementos orgánicos: «Das durch Anbildung flectirte Wort is ebenso Eins, als die verschiedenen Theile einer aufknospenden Blume es sind; und was hier in der Sprache vorgeht, ist rein organischer Natur» (Über die Verschiedenheit..., op. cit., p. 124; cursivas añadidas). Friedrich von Schlegel, en cambio, concebía los afijos como incrementos puramente mecánicos, característicos de lenguas rudas como, por ejemplo, las de los indígenas del Nuevo Mundo (F. Schlegel, Über die Sprache und Weisheit..., op. cit., pp. 60-62). 
ción de un elemento que ha perdido su significación original (Anbildung), y el de cambio interior de la palabra (innere Veraenderung), que constituye la verdadera flexión para el filólogo prusiano ${ }^{47}$.

Además, Amor Ruibal avanza, remitiendo de nuevo a Schasler, una interpretación de los tres citados grados o modos de realización de la Andeutung, que considera el eje diacrónico:

Schasler hace notar que la diferencia de estos grupos no está en la mayor o menor intimidad de enlace en sus elementos, sino exclusivamente en que estos son actualmente significativos en el primer grupo; en los idiomas del segundo, lo han sido originariamente, mientras en el tercero los elementos extraños a la raíz, jamás han tenido significación ni existencia propia ${ }^{48}$.

Acudiendo a un pasaje de la obra de Schasler, don Ángel nos aclara en qué reside la diferencia entre Anfügung y Anbildung: «La diferencia entre la flexión y el sufijo que ha perdido su significación originaria, consiste en que éste es en la flexión una creación efectiva, mientras es en otro caso una especie de transubstanciación pausada y gradual ${ }^{49}$. Amor Ruibal añade, además, una observación encaminada a discutir la posibilidad de una interpretación errada de Humboldt por parte de Schasler, contrastando manifiestamente las ideas de éste con las de Steinthal:

De ser exacta la exposición de Max Schasler, las lenguas aglutinantes y las de flexión serían para Humboldt radicalmente distintas. Sin embargo, Steinthal (Charakteristik d[er] hauptsäch [lichsten] Typen d[es] Sprachbau[e] $5^{50}$ ) hace notar estos explícitos conceptos de Humboldt, que contradicen la teoría de Schasler: «Las lenguas aglutinantes no se diferencian específicamente de las lenguas de flexión

47. CL, p. 81 .

48. CL, p. 81.

49. CL, p. 82.

50. H. Steinthal, Charakteristik der hauptsächlichsten Typen des Sprachbaues, Dümmler, Berlín, 1860. 
[...] Estas lenguas no se diferencian entre sí más que por el modo diverso, modo y medida de su perfección $»^{51}$.

En realidad, aquí, como en la mayoría de los casos, el parecer de Steinthal es mucho más fiel al espíritu de los textos humboldtianos que el juicio de Schasler. Sin embargo, de modo un tanto incomprensible, la lectura que Amor Ruibal hace de Humboldt oscila entre ambas interpretaciones, decantándose según la ocasión por una u otra conforme a una lógica que no siempre resulta clara. En todo caso, citas como la que encabeza esta nota atestiguan que Amor Ruibal no tenía un conocimiento directo de la obra de Humboldt.

En fin, llegados a este punto, podemos sintetizar mediante un esquema todas las ideas expuestas en torno a los Verfahren operativos en el nivel de la palabra:

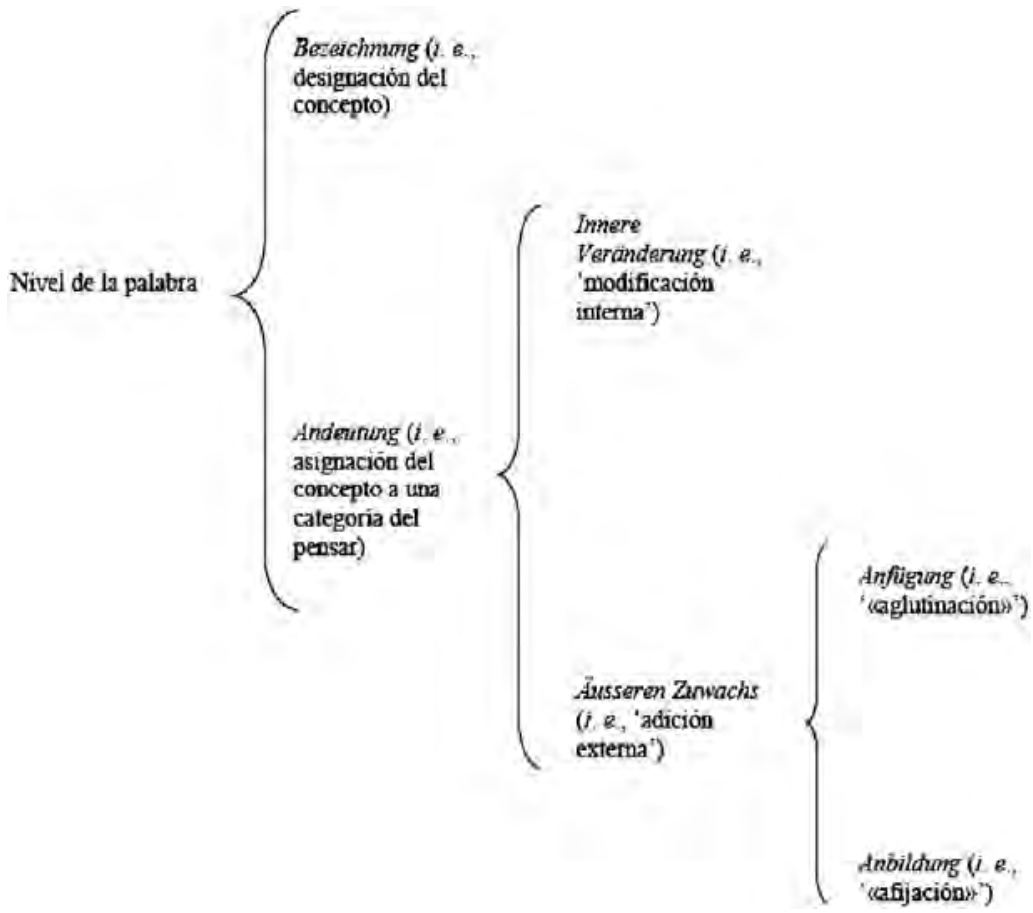


Si consideramos ahora los procedimientos o Verfahren humboldtianos por remisión a la oración, el panorama que se nos ofrece es el siguiente. Cabe hablar, en primer término, del verflechten, verbo éste que usa repetidamente Humboldt, y que puede traducirse como tejer o entrelazar. Se trataría, pues, de un procedimiento mediante el cual se entrelazan, trenzan, o tejen las relaciones de la palabra con la oración en la unidad misma de la palabra $^{52}$. Este primer método se correspondería con la flexión. En segundo lugar, encontramos casos en que la palabra no sufre modificación o alteración alguna, de modo que su engarce en la oración se lleva a cabo por medios no fónicos, principalmente mediante el orden de constituyentes ${ }^{53}$. Es el Verfahren que Humboldt llama Isolierung. Por último, habla el lingüista prusiano de un procedimiento que consiste en asegurar la unidad oracional tratando los miembros necesarios de la oración «nicht wie ein aus Worten zusammengesetztes Ganzes, sondern wirklich als ein einzelnes Wort $»^{54}$. A este tercer procedimiento Humboldt le da el nombre de Einverleibung, «incorporación», y habla, pues, como nos recuerda Coseriu ${ }^{55}$, de un Einverleibungsmethode, que ilustra con el ejemplo del azteca ${ }^{56}$. Y ha llegado el momento apropiado para resumir, por medio de otro esquema, los Verfahren humboldtianos concernientes al nivel oracional:

52. «Sprachen, die, wie das Sanskrit, schon in die Einheit des Wortes seine Beziehungen zum Satze verflechten, lassen den letzteren in die Theile zerfallen, in welchen er sich, seiner Natur nach, vor dem Verstande darstellt; sie bauen aus diesen Theilen seine Einheit gleichsam auf» (Über die Verschiedenheit..., op. cit., pp. 162-163; cf. Coseriu, «Sobre la tipología...», op. cit., p. 169).

53. «Sprachen, die, wie die Chinesische, jedes Stammwort veränderunglos starr in sich einschliessen, thun zwar dasselbe, und fast in noch strengerem Verstande, da die Wörter ganz vereinzelt dastehen; sie kommen aber bei dem Ausbau der Einheit des Satzes dem Verstande, theils nur durch lautlose Mittel, wie z. B. die Stellung ist, theils durch eigne, wieder abgesonderte Wörter zu Hülfe» (Über die Verschiedenheit..., op. cit., p. 163).

54. W. von Humboldt, Über die Verschiedenheit..., op. cit., p. 163.

55. E. Coseriu, «Sobre la tipología...», op. cit., p. 169.

56. W. von Humboldt, Über die Verschiedenheit..., op. cit., pp. 164 ss. 


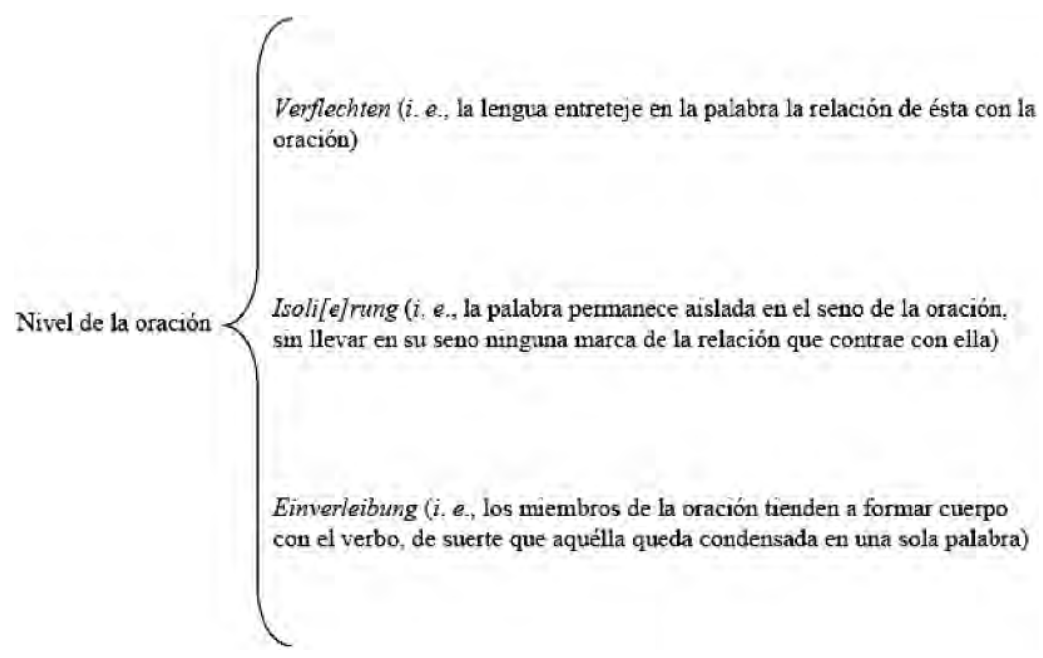

A pesar de que dichos métodos o procedimientos habilitarían diversas posibilidades de clasificación de las lenguas ${ }^{57}$, el caso es que Humboldt no sólo no da ese paso, sino que reitera en cada ocasión que se trata de Methoden o Verfahren. Sólo por entrecruzamiento de los dos niveles aquí citados, el de la palabra y el de la oración, llega Humboldt -nos recuerda, una vez más, Coseriu ${ }^{58}$ - a hablar de cuatro procedimientos para la formación de las oraciones, a saber: Isolierung, Flexion, Agglutination y Einverleibung. Así y todo, seguimos todavía en el dominio de los Verfahren. El célebre malentendido que atribuye a Humboldt una clasificación lingüística en cuatro tipos fundamentales no se originará hasta que Steinthal combine dichas etiquetas humboldtianas para los Methoden con algunas de las clases

57. Por ejemplo, tal y como sugiere Coseriu («Sobre la tipología...», op. cit., pp. 169-170), una que agrupara, por un lado, las lenguas que efectúan una separación de palabra y oración, frente a aquellas otras, las incorporantes, que no realizan dicha separación, distinguiendo ulteriormente dentro de la primera clase según los criterios de Isolierung y Verflechten flexivo, o bien una que considerara, en primer término, la oposición entre articulación no fónica de la oración y articulación expresada por medios materiales, para pasar a distinguir, dentro de este segundo término, entre Flexion y Einverleibung.

58. E. Coseriu, «Sobre la tipología...», op. cit., p. 170. 
que el lingüista prusiano adelantaba como ejemplo de una partición posible de las lenguas ${ }^{59}$.

Por último cabría hablar, a partir de los escritos de Humboldt, de una tercera acepción de la tarea tipológica, la que Coseriu comprende bajo el nombre de «tipología parcialmente caracterizante $»^{60}$. En este sentido, Humboldt admitiría clases de lenguas; ahora bien, sólo para efectuar una ulterior partición de las lenguas correspondientes al mismo Stufe ('grado'); por ejemplo, para delimitar, dentro del grado de las Partikel-Sprachen ('lenguas de partículas'), esto es, aquéllas que no

59. El famoso cuadro clasificatorio que combina la división humboldtiana entre vollkommnere Sprachen y unvollkommnere Sprachen (que es, en el fondo, una elaboración de una anterior distinción de Friedrich von Schlegel) con la designación de algunos de los Verfahren, pero como si éstos se refirieran a las lenguas, es debido, como se suele señalar, a Steinthal. Dicho cuadro lo reproduce Amor Ruibal (PFFC II, p. 386), pero se lo atribuye a Humboldt, al tiempo que (bajo el título de «Esquema de la clasificación de Steinthal») presenta una clasificación más compleja, en seis categorías, que, no obstante, aún contiene la dicotomía básica de «lenguas con forma» y «lenguas sin forma» (lenguas formales y lenguas no formales, las bautiza Amor Ruibal), que se deja retrotraer, con algunos matices terminológicos, a August Wilhelm von Schlegel. Los seis apartados de tal esquema no se corresponden término a término (aunque sí parcialmente) con la partición en cinco grupos que llegará a establecer Steinthal (cf., por ejemplo, Abriss der Sprachwissenschaft. Zweiter Teil. Charakteristik der hauptsächlichsten Typen des Sprachbaues, Dümmler, Berlín, 1893, pp. 99-110): «einverleibende Sprachen» (lenguas incorporantes, como el náhuatl); «wurzelisolierende Sprachen» (lenguas aislantes-radicales, como el chino o el tailandés); «stamm-isolierende Sprachen» (lenguas aislantes-temáticas, como el malayo); «anreihende Sprachen» (lenguas seriantes, como las de la familia bantú); «agglutinierende Sprachen» (lenguas aglutinantes, como las de las familias uraloaltaica y dravídica); «flektierende Sprachen» (lenguas flexivas, como las de las familias semítica e indoeuropea). Por si no hubiera ya bastante confusión en torno a este importante episodio de la historia de la lingüística (cuyos ecos terminológicos y, a veces, conceptuales llegan a nuestros días) resulta que se cita por doquier (Coseriu incluido; cf. «Sobre la tipología...», op. cit., p. 180) el cuadro de Steinthal sobre Humboldt como extraído de la página 70 de Charakteristik der hauptsächlichsten Typen des Sprachbaues. Nosotros, consultando la edición que acabamos de citar, supervisada por el profesor Franz Misteli (1841-1903), no encontramos ese cuadro clasificatorio, no ya en la página 70 , sino en toda la obra. Sí lo hallamos, en cambio, en la última página de «Der heutige Zustand der Sprachwissenschaft» (Allgemeine Monatsschrift für Literatur, I, 1850, pp. 97-110, 208-217). Dicho trabajo se ha reproducido en H. Steinthal, Kleine.., op. cit., pp. 114-138).

60. E. Coseriu, «Sobre la tipología...», op. cit., p. 182. 
distinguen entre el nombre y el verbo ${ }^{61}$. En todo caso, de ello no se desprendería una clasificación stricto sensu de las lenguas del globo ${ }^{62}$.

Habiendo aclarado los diversos sentidos o direcciones en que cabe entender la idea de tipología en Humboldt, cumple ahora preguntarse: ¿en qué acepciones se emplea el término en Amor Ruibal? ¿Qué acepción de la empresa tipológica domina en su obra? Puede argüirse, sin demasiada dificultad, que es el segundo de los sentidos, el de los modos generales de estructuración lingüística, el que aparece de manera primordial y casi única en sus páginas. Al margen de referencias difusas a la innere Sprachform, no encontramos elementos que nos permitan aseverar que Amor Ruibal había avanzado de modo significativo y preciso en la primera dirección tipológica. Y sus clasificaciones, tomadas de Schleicher, de Friedrich Müller y de Steinthal, pretenden serlo en el sentido habitual del término. No hay nada ahí tampoco, pues, que nos pueda hacer pensar que nuestro autor fuera sensible a la dirección tipológica que Coseriu denomina «parcialmente caracterizante».

Sí es, en cambio, sensible a los Verfahren o Methoden humboldtianos. Y ello de un modo harto llamativo. Porque, a pesar de caer en ocasiones en el error crónico de interpretar las designaciones como referidas a las lenguas, y no a formas de organización gramatical (un error del que, como hemos visto, no estaban libres los filólogos de los que bebe Amor Ruibal, ni aun autor alguno del siglo XIX alemán posterior a Humboldt, podemos decir sin temor a equivocación), nuestro autor muestra otras veces un buen sentido admirable que le lleva a no olvidar el carácter de procedimientos o Verfahren que ha de otorgarse a términos como Agglutination o Flexion. Ya hemos dicho con anterioridad que Amor Ruibal es consciente del doble plano de articulación de la palabra, como Bezeichnung y como Andeutung. En este punto es fiel al espíritu humboldtiano. Sin embargo, no puede pasarnos desapercibido un hecho sorprendente que ha de constituir un aspecto central de

61. Como, por ejemplo, el birmano. «Unter allen, mir genauer bekannten Sprachen -dice Humboldt (Über die Verschiedenheit..., op. cit., pp. 333-334)- mangelt keiner so sehr die formale Bezeichnung der Verbalfunction, als der Barmanischen». En cuanto a la etiqueta Partikel-Sprachen, parece haber sido creada por Steinthal (podemos encontrarla, por ejemplo, en el cuadro mencionado supra, en la n. 58).

62. Cf. E. Coseriu, «Sobre la tipología...», op. cit., pp. 181-182. 
cualquier investigación futura que se avenga a tratar en profundidad la tipología en Amor Ruibal, aquí apenas esbozada: no se encuentran huellas de los Methoden o Verfahren al nivel de la oración. Ello es tanto más llamativo cuanto que nuestro autor no duda, a lo largo de sus páginas, en colocar la oración (vale decir, la «frase»), en el centro de los estudios lingüísticos ${ }^{63}$. La frase, nos dice, otorga sentido a las palabras, que en puridad nada son fuera de ella. La frase es, además, el lugar en que confluyen el juicio lógico, el pensamiento, la representación psíquica verbal o dicente, y la expresión formal. Y, comoquiera que la ciencia del lenguaje que nuestro autor pretende fundamentar ha de tener como fin último -piensa él- el desentrañamiento de la naturaleza esencialmente psicológica del lenguaje, los citados Verfahren o procedimientos de engarce de la palabra en la oración deberían ocupar un primer plano. Así ha de ser por la metodología que Amor Ruibal despliega a lo largo de sus dos libros. No por casualidad, al iniciar su extenso repaso histórico del lugar de la filología y la reflexión sobre el lenguaje en la Antigüedad, nos había dicho: «El método seguido por los griegos prestábase a favorecer el desarrollo de la sintaxis, que por su carácter es más accesible a las especulaciones psicológicas $»^{64}$.

Pero de hecho salta a la vista este hueco empírico en sus páginas. Por si el asunto fuera poco estupefaciente, resulta que Steinthal (de quien tantas ideas adopta Amor Ruibal, como hemos visto) dedica una parte no poco importante del primer volumen de su Abriss der Sprachwissenschaft ${ }^{65}$, a discutir las conexiones de los momentos psíquicos ligados, por así decirlo, mediante el hilo del

63. «[L]a sintaxis - escribe don Ángel (PFFC I, 356 n. 1)- encierra la razón formal de los idiomas y su valor ideológico, que es, en resumen, el valor único que los caracteriza; si puede haber idiomas sin morfología (los monosilábicos) no los hay ni puede haberlos sin sintaxis. En este sentido es muy verdadero que las lenguas nunca comienzan sino por la frase, esto es, que ya se trate de una o muchas palabras, y sean éstas de cualquier condición, siempre han de representar ideas, juicios, o raciocinios, o sea frases completas, que por lo mismo son sintácticas. Entendida de esta suerte la afirmación de Sayce ([The] Principles [of comparative philology, Trübner \& Co., Londres, 1874, p. 131]) [de] que los primeros elementos de las lenguas son frases, no podría negarse».

64. CL, p. 10 n. 1.

65. H. Steinthal, Abriss der Sprachwissenschaft. Erster Band. Einleitung in die Psychologie und Sprachwissenschaft, Dümmler, Berlín, 1881. 
lenguaje $e^{66}$. Y hete aquí que la Verflechtung, el tejimiento, entretejimiento o entrelazamiento que viéramos al tratar los Methoden de la oración en Humboldt, hace aquí acto de presencia. Presencia primordial, como la de la Verschmelzung, la amalgama o fusión, que Humboldt usara en un contexto puramente morfológico, y que en Steinthal remite a las representaciones (Vorstellungen). Se trata, en realidad, de algo más que una simple coincidencia en el nombre. En efecto, algunos de los procedimientos de la mecánica psíquica de Steinthal, como la «asociación», con sus correspondientes direcciones, están muy presentes en el nacimiento de la lingüística general a principios del siglo xx. Con Saussure, ciertamente, por medio de Émile Durkheim (1858-1917) entre otros, pero también con el Louis Hjelmslev (1899-1965) de los Principes de grammaire générale ${ }^{67}$. Y las ideas de Übertragung ('transferencia' o, en algunos contextos, 'proyección') y Hineintragen ('introyección'), también articuladas en Steinthal, serán decisivas en Sigmund Freud (1856-1939). Todo ello hace aún más sorprendente el vacío o silencio que se encuentra en Amor Ruibal en este punto. Averiguar sus motivos -dado que la enorme extensión de su obra lingüística parece desaconsejar desde ya la idea de una omisión puramente accidental- ha de constituir uno de los aspectos decisivos de futuras investigaciones ${ }^{68}$.

66. Se ocupa de la cuestión en la segunda parte del primer volumen, titulada «Psychische Mechanik» (H. Steinthal, Abriss der Sprachwissenschaft. Erster Band. Einleitung..., op. cit., pp. 91-289).

67. L. Hjelmslev, Principes de grammaire générale, Danske Videnskabernes Selskab, Copenhague, 1928.

68. Quedará para otro momento el informe sobre el cotejo minucioso de todas las citas amorruibalianas en lo que concierne a la tipología con los originales consultados y con el índice del catálogo de su biblioteca, tal y como fue recopilado por Saturnino Casas Blanco (1913-?) («El catálogo de la biblioteca de don Ángel Amor Ruibal», Pensamiento, XXV/100, 1969, pp. 371-402; «El catálogo de la biblioteca de don Ángel Amor Ruibal (continuación)», Pensamiento, XXVI/101, 1970, pp. 33-71). En este punto me gustaría agradecer al profesor Johannes Kabatek, de la Universität Tübingen, la amabilidad y gentileza que para conmigo tuvo al facilitarme una copia del texto de Casas. Sobre dicho cotejo daré cumplida y extensa cuenta en otra publicación futura, si el presente texto no cae del todo en saco roto. Allí trataré de mostrar cómo algunas de las carencias más importantes en los trabajos lingüísticos de Amor Ruibal (sobre todo, en Los problemas fundamentales de la filología comparada) se subsanan si se aviene uno a pensar que nuestro autor dialoga, omitiendo todo aquello que sea un fácil sobreentendido, con Friedrich Müller. 